\title{
Power Electronics Solutions for Smart Grids: A Perspective From Design to Pre-Industrial Prototypes
}

\begin{abstract}
The Group of Energy and Power Electronics (GEPE) is a research group at the University of Minho, Portugal. The main research fields are centered in the development of power electronics solutions for power quality technologies (software and hardware equipment for monitoring and for compensating power quality problems), renewable energy technologies, mainly for on-grid and off-grid interface of photovoltaic and micro wind turbines (including solutions for energy storage), electric mobility technologies (battery chargers, traction systems, wireless power transfer solutions), as well as consulting services of power quality and energy efficiency. As demonstrated in the scope of several projects, the GEPE is well prepared with the necessary equipment and knowledge to support the development of software and hardware structures up to a pre-industrial phase, and to perform the experimental validation of systems based on power electronics. GEPE also has know-how in different tools for supporting the simulation of the electronic systems, and for programming a wide range of digital platforms. In the scope of this demo, the GEPE will introduce emerging technologies about power electronics solutions and trends for technological developments that will guide and reinforce the achievement of a smart city encompassed in a smart grid. Therefore, a detailed explanation will be conducted showing some of the developed power electronics prototypes, based on proprietary software and hardware.
\end{abstract}

Keywords: Power Electronics, Smart Cities, Smart Grids. 
1 Photos Showing the GEPE Laboratory
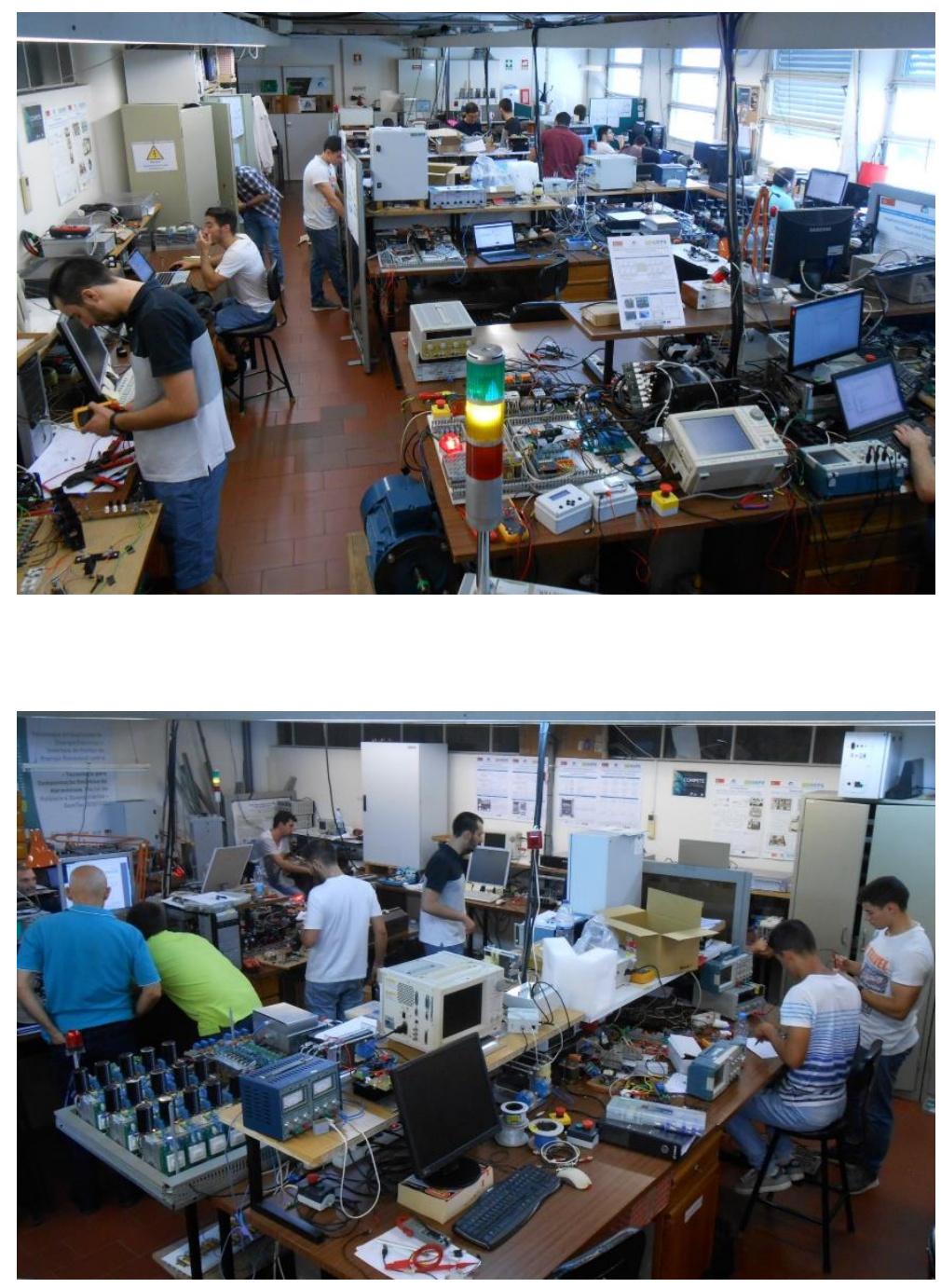
2 Photos Showing the Power Converters and Boards

Examples of Power Converters

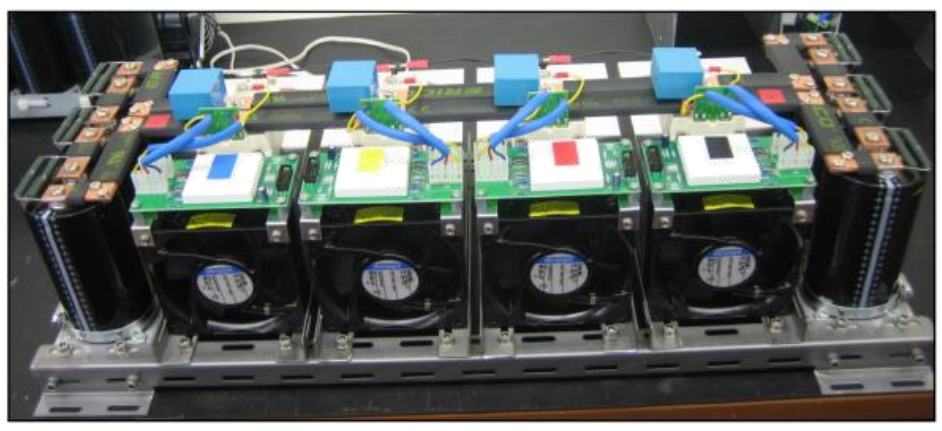

DSP and Signal Conditioning Boards

Command Board
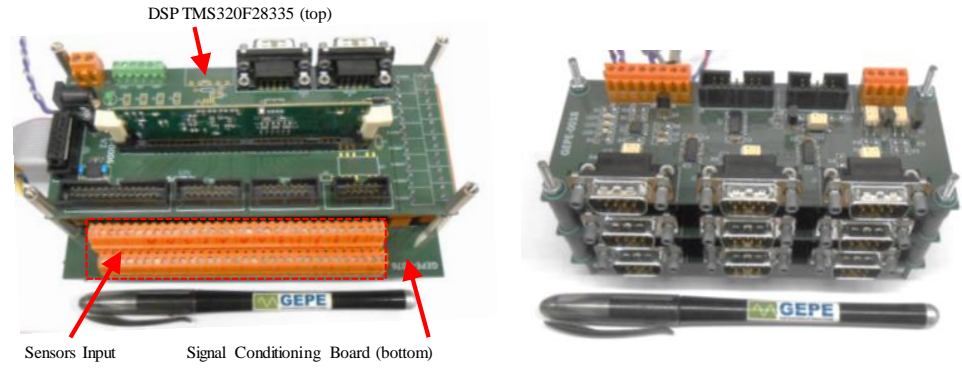

External ADCs board

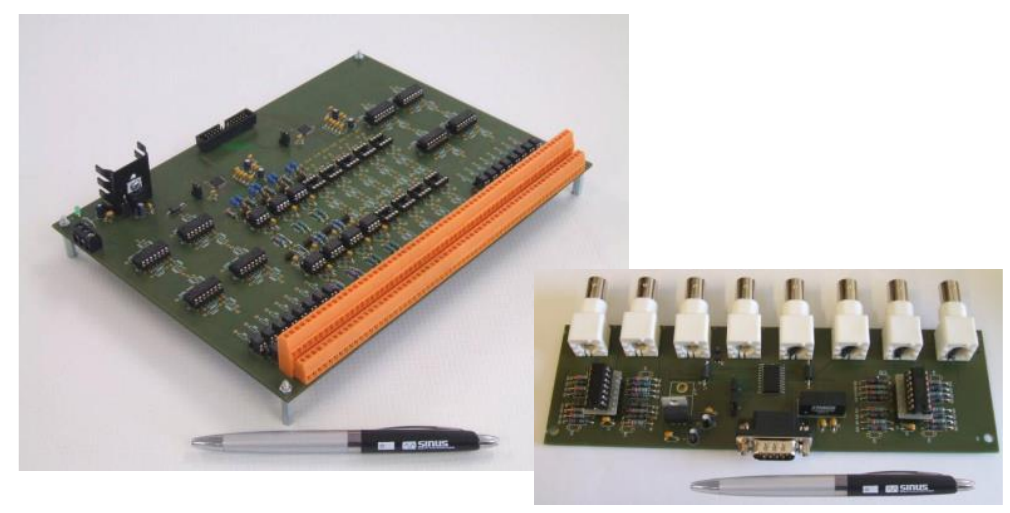

DAC board 


\section{Photos Showing Prototypes}

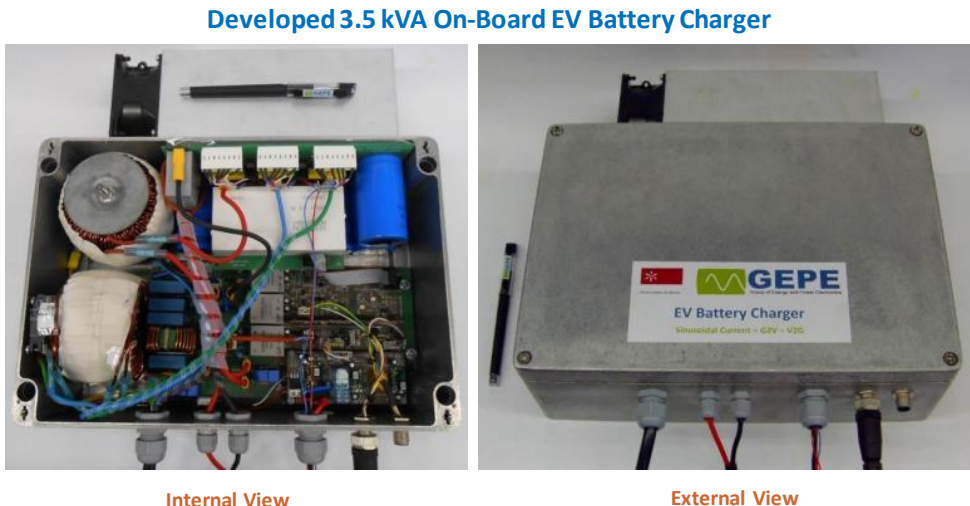

Portable Power Quality Monitor
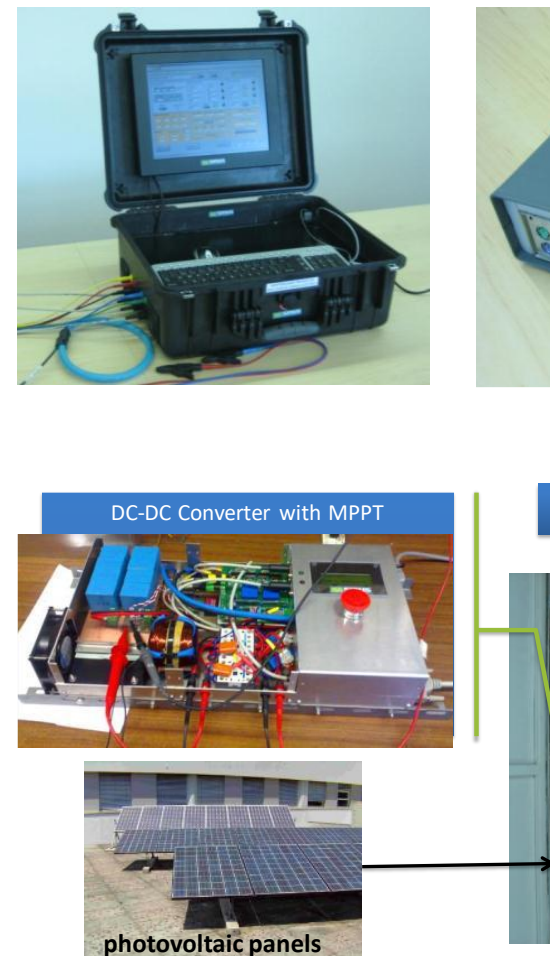
Power Quality Monitor
embed in Active Power Filters
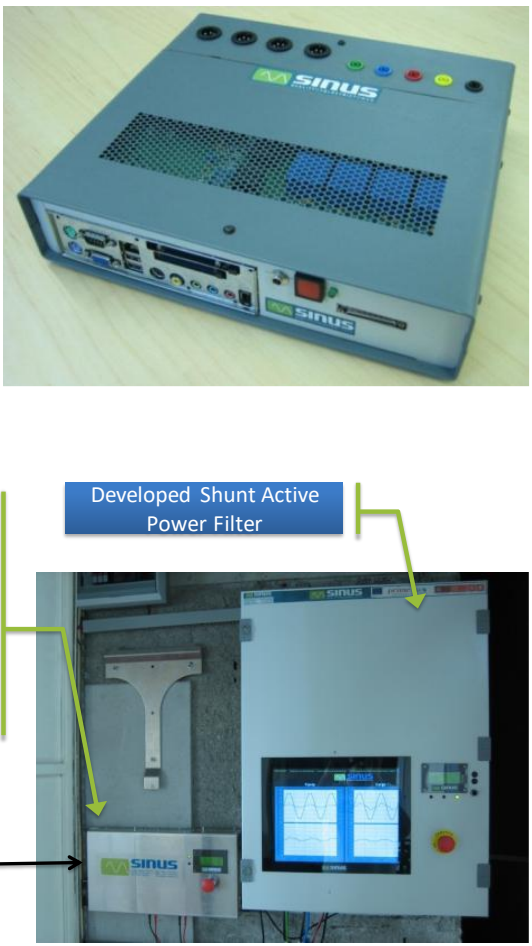


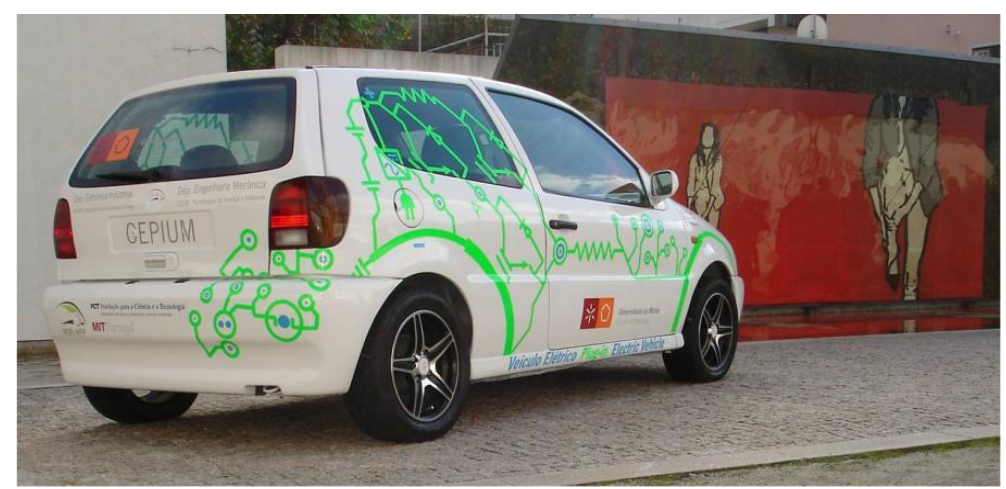

https://www.gepe.dei.uminho.pt/cepium/

C E PI U M - CARRo Elétrico PLUG-IN DA UNIVERSIDAde Do MinHo PLUG-IN ELECTRIC VehicLE OF THE UNIVERSITY OF MINHO

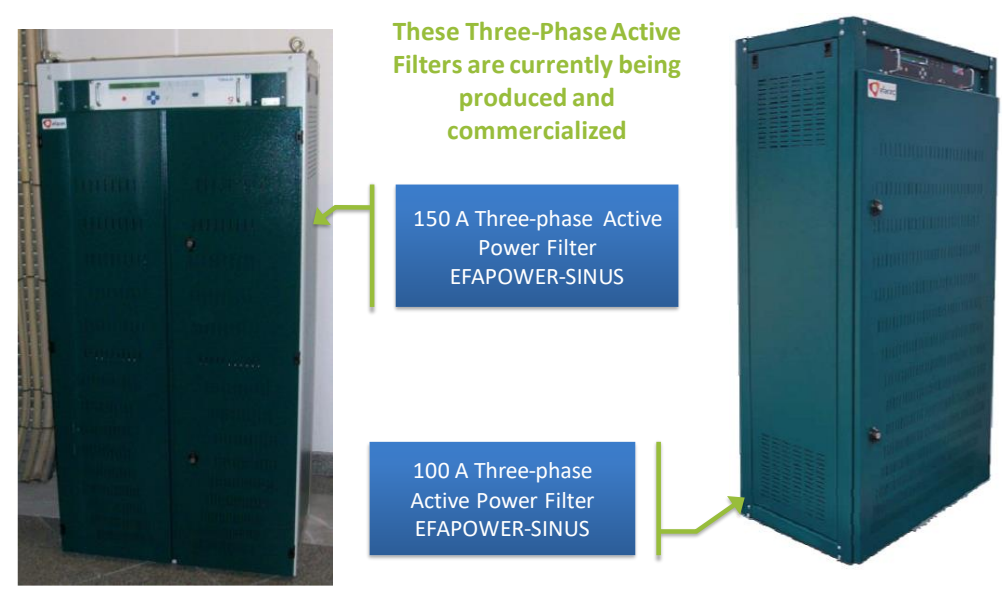

Developed Power Electronics for the Electric Bike BEUM
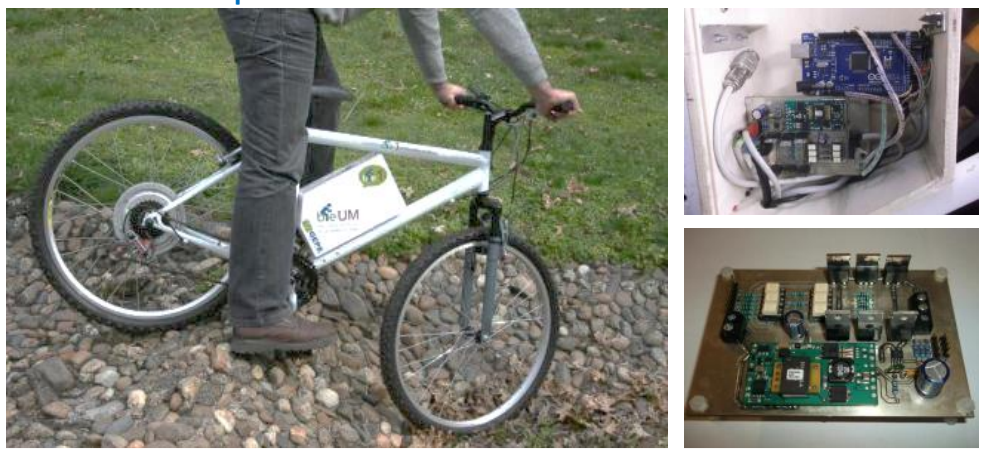